\title{
Políticas curriculares para o Ensino Médio nas escolas do campo no Brasil
}

\author{
Curricular policies for Secondary Education in rural schools in Brazil
}

\section{Políticas curriculares para la Enseñanza Media en las escuelas rurales en Brasil}

\author{
Paoline Bresolin'
}

Prefeitura Municipal de Erechim, Professora de Educação Infantil

\author{
Chaiane Bukowski ${ }^{2}$ \\ Universidade Federal da Fronteira Sul, Professora Substituta da área das Ciências Humanas \\ Roberto Rafael Dias da Silua ${ }^{3}$ \\ Universidade do Vale do Rio dos Sinos, Professor no Programa de Pós-Graduação em \\ Educação
}

Resumo: Neste estudo aborda-se uma reflexão de caráter empírico sobre as orientações legais e propostas educacionais para o Ensino Médio do Campo, considerando as políticas públicas que fazem parte do quadro governamental atual. Procurou-se elencar como foco analítico da pesquisa as teorizações sobre a constituição do conhecimento escolar na referida etapa da Educação Básica. Com base nas dimensões atuais que vêm caracterizando o Ensino Médio, em aproximação à Educação do Campo, compomos um diagnóstico sobre os princípios e fundamentos que norteiam o processo pedagógico e conduzem o sistema escolar no âmbito em questão. Para tanto, decidimos descrever, examinar e problematizar as concepções de conhecimento escolar em documentos de caráter nacional, a fim de verificar os sentidos e as tendências que influenciam os rumos do processo de decisão curricular nas escolas. A presente investigação revelou que, mesmo considerando os avanços que promoveram melhorias no Ensino Médio do Campo, as estratégias para a democratização e a qualificação do ensino são limitadas e insuficientes,

\footnotetext{
Mestre em Educação pelo Programa de Pós-Graduação em Educação na Universidade Federal da Fronteira Sul; Pós-graduada em Processos Pedagógicos na Educação Básica pela Universidade Federal da Fronteira Sul.

2 Mestre em Educação pela Universidade Federal da Fronteira Sul; Especialista em Educação Integral pela Universidade Federal da Fronteira Sul.

3 Doutor em Educação pela Universidade do Vale do Rio dos Sinos; Mestre em Educação pela Universidade do Vale do Rio dos Sinos.
} 
já que as teorizações dos Estudos Curriculares indicam para uma educação comprometida com o conhecimento escolar e a consequente possibilidade de os estudantes intervirem no mundo de forma qualificada e crítica.

Palavras-chave: Currículo do Ensino Médio. Educação do Campo. Conhecimento escolar.

Abstract: This study addresses an empirical reflection on the legal guidelines and educational proposals for Secondary Education in Rural Areas, considering public policies that are part of the current governmental context. It seeks to list as an analytical focus of the research the theories on the formation of school knowledge in that stage of basic education. Based on the current dimensions that have characterized Secondary Education regarding Rural Education, we compose a diagnosis on the principles and foundations that guide the pedagogical process and lead the school system in the context in question. To that end, we decided to describe, examine and discuss the concepts of school knowledge in documents of national character, in order to determine the meanings and trends that influence the course of curriculum decisionmaking in schools. This investigation has revealed that, even considering the advances that have promoted improvements in Secondary Education in Rural Areas, strategies for education democratization and qualification are limited and insufficient, since the theorizing of Curriculum Studies points towards an education committed to school knowledge and the consequent possibility of students intervening in the world in a skilled and critical manner.

Keywords: Secondary Education curriculum. Education in Rural Areas. School knowledge.

Resumen: Este estudio aborda una reflexión de carácter empírico sobre las orientaciones legales y propuestas educacionales para la Enseñanza Media de la Zona Rural, considerando las políticas públicas que forman parte del marco gubernamental actual. Se busca enumerar como enfoque analítico de la investigación las teorizaciones sobre la constitución del conocimiento escolar en dicha etapa de la Educación Básica. Con base en las dimensiones actuales que caracterizan la Enseñanza Media, acercándose a la Educación en la Zona Rural, componemos un diagnóstico sobre los principios y fundamentos que guían el proceso pedagógico y conducen el sistema escolar en el ámbito en cuestión. Para ello, decidimos describir, examinar y problematizar las concepciones de 
conocimiento escolar en documentos de carácter nacional, a fin de verificar los sentidos y tendencias que influyen en los caminos del proceso de decisión curricular en las escuelas. La presente investigación reveló que, aunque se considere los avances que promovieron mejoras en la Enseñanza Media de la Zona Rural, las estrategias para democratización y la cualificación de la enseñanza son limitadas e insuficientes, ya que las teorizaciones de los Estudios Curriculares indican una educación comprometida con el conocimiento escolar y la consecuente posibilidad de que los estudiantes intervengan en el mundo de forma cualificada y crítica.

Palabras clave: Currículo de la Enseñanza Media. Educación en la Zona Rural. Conocimiento escolar.

\section{INTRODUÇÃO}

[... ] a escola é o tempo e o lugar para estudo e prática - as atividades escolares que podem alcançar um significado e um valor em si mesmas. (MASSCHELEIN; SIMONS, 2014, p. 40).

Este artigo se inscreve no campo dos estudos curriculares e, considerando os direcionamentos das políticas educacionais para o Ensino Médio e para a Educação do Campo, privilegia os estudos e as conceitualizações sobre o conhecimento escolar. Nossa problematização evidencia as transformações organizacionais, legais e pedagógicas dessa etapa da Educação Básica, atentando para ações e princípios que indicam a preocupação "com uma melhor definição de seus propósitos e, ademais, com a melhoria da qualidade do ensino ofertado." (MOEHLECKE, 2012, p. 42). No que se refere à Educação do Campo, faz-se possível reconhecer, no processo histórico, que o seu sistema escolar se constituiu como adaptação das escolas urbanas (ALMEIDA, 2011 ).

Por isso, sinalizamos importantes avanços no atual cenário brasileiro, principalmente em relação ao reconhecimento de seus domínios e singularidades, identificando, também, os diferentes desafios que as escolas localizadas nas áreas rurais vêm enfrentando. Diante desses apontamentos, os 
principais objetivos com este estudo foram descrever, examinar e problematizar as concepções de conhecimento escolar nos documentos publicados pelo Ministério da Educação, os quais, ao orientar o Ensino Médio e a Educação do Campo, prescrevem racionalidades políticas e influenciam o processo de escolha nos diferentes âmbitos de decisão curricular.

Para este texto, mobilizamos nosso pensamento de forma crítica, salientando que "os alunos não vão à escola para aprender o que eles já sabem" (YOUNG, 201 l, p. 403), pressupondo que as experiências e os conhecimentos que eles trazem da sua vida cotidiana devem ser apenas parte dos recursos que os professores possuem na configuração do currículo. Assim, a premissa que sustenta nosso debate está atada à discussão de defender um ensino que leve os estudantes para além de suas vivências pessoais. Nessa direção, Krawczyk (2011, p. 757) argumenta que "quando os adolescentes que agora estão ingressando no ensino médio realmente aprenderem em sintonia com o mundo em que vivem, estaremos diante de um processo real de democratização do ensino e não simplesmente de progressiva massificação."

Foi por essa razão que escolhemos como epígrafe para este artigo os escritos recentes de Masschelein e Simons (2014), pois, de um ponto de vista filosófico, instigam-nos a promover "exercícios de pensamento" em torno das possibilidades de uma escola mais aberta e plural, que seja capaz de "suspender outras finalidades", valendo-se de outras configurações de tempo. Segundo os autores, "a escola cria igualdade precisamente na medida em que constrói o tempo livre, isto é, na medida em que consegue, temporariamente, suspender ou adiar o passado e o futuro, criando, assim, uma brecha no tempo linear." (MASSCHELEIN; SIMONS, 2014, p. 36). Considerando a relevância dessa concepção educacional, seguiremos pensando as relações entre os currículos escolares para o Ensino Médio e a Educação do Campo.

Para esta pesquisa, optamos por analisar os documentos que regem - Ensino Médio do Campo, a fim de verificar quais são os seus principais direcionamentos quanto às políticas governamentais e às orientações legais. Selecionamos os documentos publicados em nível nacional, organizados pelo Ministério da Educação (MEC), que tecem considerações sobre a temática deste estudo. Dessa forma, nosso corpus de análise compreende os seguintes 
documentos: as Diretrizes Curriculares Nacionais para o Ensino Médio, conforme o disposto na Resolução CNE/CEB n. 2, de 30 de janeiro de 2012 (MINISTÉRIO DA EDUCAÇÃO, 2012b), e no Parecer CNE/CEB n. 5, de 04 de maio de 2011 (MINISTÉRIO DA EDUCAÇÃO, 2012a), e os Marcos Normativos, organizados pelo Ministério da Educação em 2012, os quais contêm oito documentos orientadores da Educação do Campo. Optamos por analisar apenas os que tratam do Ensino Médio. São eles: Resolução CNE/CEB n. 1, de 03 de abril de 2002 (MINISTÉRIO DA EDUCAÇÃO, 2002); Parecer CNE/CEB n. 1, de 01 de fevereiro de 2006 (MINISTÉRIO DA EDUCAÇÃO, 2006); Resolução CNE/CEB n. 2, de 28 de abril de 2008 (MINISTÉRIO DA EDUCAÇÃO, 2008); e Decreto n. 7.352, de 04 de novembro de 2010 (BRASIL, 2010).

Observando tais aspectos, organizamos o presente estudo em três momentos. Iniciamos com um breve debate histórico que articula a Educação do Campo e o Ensino Médio, salientando os principais acontecimentos constituintes dessa trajetória. Na sequência, apresentamos os programas governamentais implementados pelo Estado brasileiro, assinalando suas eventuais contribuições para o Ensino Médio no Campo. No terceiro momento, enfatizamos aspectos relacionados ao currículo, sinalizando apontamentos empíricos por meio da análise dos documentos que orientam o Ensino Médio no Campo. Cumpre reiterar nossa preocupação analítica com o mapeamento das racionalidades políticas que orientam a seleção dos conhecimentos escolares nesse nível e modalidade de ensino. Seguiremos questionando, enfim, as possibilidades de constituição de uma pauta pública para a escolarização dos jovens brasileiros.

\section{EDUCAÇÃO DO CAMPO E ENSINO MÉDIO: DEBATES E COMPREENSÕES HISTÓRICAS}

$\mathrm{Na}$ amplitude dos estudos que abordam aspectos históricos da Educação do Campo, encontramos em pesquisas de vários autores indicativos de que o espaço rural tenha sido secundarizado no processo de configuração da sociedade brasileira; dentre estes, poderíamos referir os desenvolvidos por 
Calzanas (1993), Almeida (2011), Molina e Freitas (201 1) e Romanelli (2012). Almeida (201 1, p. 279) aponta que houve "uma tendência da 'cidade' assumir uma posição de guia, de condutora das populações, indicando os caminhos a serem seguidos." $\bigcirc$ que contribuiu para esse quadro de predominância do contexto urbano foram, principalmente, as exigências da acelerada mudança estrutural da sociedade no final do século XIX e no início do século XX, com a emergência da industrialização (SOUZA, 2008). De acordo com essa literatura, ocorreu um aumento significativo do número de pessoas que migraram do campo para a cidade, caracterizando a passagem de um modelo agrário para o industrial: "o Brasil era um país nitidamente rural e assim se manteve até a década de 1920, mas a cada novo período a tendência irreversível foi o aumento da população urbana e o decréscimo da população rural." (ALMEIDA, 2011 , p. 279). Isso aconteceu, principalmente, porque as pessoas viam na cidade uma possibilidade única para se estabelecerem; porém, esses migrantes do campo encontraram nas cidades condições de vida precárias, e o trabalho nas fábricas era massivo. Com isso, surgiu a necessidade de oferecer qualificação mínima para o trabalho e eliminar o analfabetismo, oferecendo uma formação que contemplasse o maior número de pessoas possível (ROMANELLI, 2012).

Por esse viés, percebemos que a modernização havia modificado muitas das referências sociais, econômicas, políticas e educacionais. Romanelli (2012, p. 59) complementa que "as mudanças ocorridas na escola, em atendimento às exigências da demanda, foram predominantemente quantitativas. Precisamente como aconteceu com os padrões de consumo, os padrões de educação foram determinados pelo fator demanda." Assim, o sistema escolar passou a implantar o ensino profissionalizante para os "menos favorecidos", modificando os conteúdos a fim de adaptá-los às demandas do momento. Desse modo, o ensino secundário, que antes era destinado somente para a elite, agora se dividia em dois modelos: para os menos favorecidos financeiramente, era ofertado o ensino profissionalizante, objetivando qualificar mão de obra de forma acelerada e seguindo as exigências do mercado de trabalho; simultaneamente, o ensino propedêutico, destinado para a classe mais abastada, visava dar continuidade aos estudos com ingresso nas universidades para posteriormente conseguirem os melhores cargos profissionais (MOEHLECKE, 2012). Diante desse cenário, 
de acordo com Silva Júnior e Borges Netto (201 1), o Estado brasileiro não se constituiu em um espaço de ações planejadas e institucionalizadas para a educação no meio rural.

No ano 1927, a Primeira Conferência Nacional de Educação foi realizada em consonância com o Movimento da Escola Nova e significou o início das preocupações com o ensino no meio rural. Em tal evento, chegou-se ao entendimento de que "era preciso uniformizar por um lado, mas diferenciar por outro, uniformizar valores e sentimentos da cultura nacional e diferenciar a formação específica do aluno que frequentava escolas no campo ou nas cidades." (ALMEIDA, 201 l, p. 283). Porém, ações pouco efetivas, associadas à infraestrutura inadequada, ausência de materiais didáticos, entre outros problemas, continuaram a marcar o contexto rural na década de 1940, quando a escola ainda se configurava dentro de um sistema seletivo. Então, cabia ao professor a responsabilidade de lutar por melhores condições, a fim de incorporar valores para guiar a sociedade (ALMEIDA, 2011). Os currículos da cidade e do campo não se diferenciavam, uma vez que era de incumbência da escola ensinar conhecimentos básicos, visto que se o aluno fosse para a cidade teria habilidades para conseguir se adaptar ao novo contexto.

Tornou-se notável, na década de 1960, a Lei de Diretrizes e Bases (Lei n. 4.024, de 20 de dezembro de 1961), a qual contribuiu para a organização do sistema escolar, observando o contexto social. Ao que se refere à educação no meio rural, Romanelli (2012, p. 188) aponta que uma das únicas vantagens dessa Lei foi "não ter prescrito um currículo fixo e rígido para todo o território nacional, em cada nível e ramo. [...] As escolas acabaram compondo o seu currículo de acordo com os recursos materiais e humanos de que já dispunham." A reforma propôs mudanças na organização do ensino secundário, seguindo o interesse dos grupos conservadores. Ela objetivou um projeto educacional capaz de contemplar a formação de jovens para atuar no mercado de trabalho, vislumbrando o desenvolvimento social (SOUZA, 2008). A promulgação dessa Lei "veio, então, conferir maior homogeneidade escolar a este campo e, ainda, um caráter mais universal ao ensino técnico." (RAMOS, 201 l, p. 232). Em tais condições históricas, entendemos que o Estado passou a se preocupar com a Educação Rural e sua qualidade, com o propósito de encontrar estratégias para 
diminuir a migração de pessoas que saíam do campo em busca de melhores oportunidades nas cidades. Partindo desse pressuposto, compreendemos que a Educação do Campo ingressou no conjunto das preocupações do Estado brasileiro, associada a políticas de permanência da população em áreas rurais, de forma que combatessem o crescente "êxodo rural".

Posteriormente, na década de 1970, o currículo do Ensino Médio foi geralmente estruturado vinculado aos modelos pedagógicos do tecnicismo. A aprovação da Lei n. 5.692, promulgada em 11 de agosto de 1971 (Lei de Diretrizes e Bases - LDB), destacava essa questão e determinava que "o Ensino Médio tivesse a terminalidade como característica básica, através do ensino profissionalizante, contrapondo-se à frustração da falta de uma habilitação profissional. Pretendia-se também adotar o ensino técnico industrial como modelo implícito." (NASCIMENTO, 2007, p. 83). Em seu art. 4 , o documento sinalizava a estruturação das propostas curriculares no que se refere ao ensino de $1^{\circ}$ e $2^{\circ}$ Graus, afirmando que estes teriam "um núcleo comum, obrigatório em âmbito nacional, e uma parte diversificada para atender, conforme as necessidades e possibilidades concretas, às peculiaridades locais, aos planos dos estabelecimentos e às diferenças individuais dos alunos." (BRASIL, 1971).

Mesmo que muitos avanços tenham sido previstos, Romanelli (2012), em sua retomada histórica, indica que, para o contexto rural, o estabelecido na lei foi uma incoerência, pois os recursos humanos e materiais disponíveis nessas escolas não dariam conta de integrar as reformas mencionadas. Mais tarde, a Lei de Diretrizes e Bases n. 9.394, de 20 de dezembro de 1996. apontou mudanças para o ensino dos jovens, uma vez que "em nenhuma das perspectivas anteriores o projeto de Ensino Médio esteve centrado na pessoa humana." (RAMOS, 201 l, p. 240). Em outras palavras, passa-se a compreender que essa etapa da Educação Básica necessita formar para a vida, diferentemente das outras propostas, as quais visavam à preparação profissional. De acordo com a legislação, no que se refere ao Ensino Médio brasileiro, este ficou sob responsabilidade do Governo Federal, que acaba o repassando para os estados.

A década de 1990 foi marcada por uma das ações mais notáveis que envolveram o campo e, consequentemente, debates e melhorias: a I 
Conferência Nacional: Por uma Educação Básica do Campo, ocorrida em julho de 1998 em Luziânia (GO). Um dos principais objetivos apresentados era "ajudar a recolocar o rural, e a educação que a ele se vincula, na agenda política do país." (KOLLING; NÉRY; MOLINA, 1999, p. 22). Além disso, a referida conferência envolvia propostas de transformação curricular e das práticas pedagógicas, além de formação global dos estudantes, integrando o trabalho com a terra, com a cultura e a história do seu povo. Em consonância a esse processo, a aprovação do Parecer CNE/CEB n. 36, de 04 de dezembro de 2001 - que estabelece as Diretrizes Operacionais para a Educação Básica nas Escolas do Campo (MINISTÉRIO DA EDUCAÇÃO, 2002) - apontou para a consolidação de uma política pensada para o campo e para a educação que ali era oferecida.

No presente decurso histórico, faz-se possível destacar que muitos avanços na escolarização ocorreram de maneira desigual e tardia. Em face dessa realidade, podemos evidenciar a Emenda Constitucional n. 59, que promulgou a obrigatoriedade dessa etapa da Educação Básica para jovens, aprovada somente em 2009 (MOEHLECKE, 2012). A literatura contemporânea assinala a necessidade de encontrar os sentidos para essa etapa da escolarização, uma vez que o Ensino Médio "nunca teve uma identidade muito clara, que não fosse um trampolim para a universidade ou a formação profissional." (KRAWCZYK, 2011, p. 755).

Diante desses aspectos, compreendemos que o Ensino Médio do Campo se configurou dentro de um contexto cultural, político, social e escolar que operou mecanismos determinantes para o seu desenvolvimento. Assim, as decisões curriculares, como parte de práticas variadas, não se resumem apenas às pedagógicas, mas envolvem ações de ordem política, administrativa, de avaliação e de ensino que, de uma forma ou de outra, incidem na prática escolar (SACRISTÁN; GÓMEZ, 1998). Dessa forma, os conhecimentos a serem ensinados e os conteúdos selecionados voltam-se a diferentes racionalidades, ampliando os valores que a escola deveria atender, passando a assumir multiplicidades contraditórias dos seus reais objetivos (SACRISTÁN, 2013). Então, em muitos casos, os princípios que regem o campo de ação dos alunos e professores não proporcionam condições para a produção de identidades e 
cultura, distanciando a escola da socialização dos conhecimentos. Abordaremos a seguir as políticas de desenvolvimento que enfatizam a constituição do Ensino Médio no Campo, apresentando as ações governamentais por meio dos programas e projetos educacionais.

\section{PROBLEMATIZAÇÕES CONTEMPORÂNEAS ACERCA DAS POLÍTICAS DE DESENUOLUIMENTO PARA O ENSINO MÉDIO DO CAMPO}

Por uma leitura historiográfica, evidenciamos a persistência de desigualdades na constituição das escolas do campo em relação às da cidade. Entretanto, atualmente, observamos investimentos, ações e programas governamentais que enfatizam o ensino na área rural, visando melhorar a qualidade e assegurar o acesso e a permanência dos estudantes que cursam a última etapa da Educação Básica. Desse modo, delineamos, nesta seção, características e sentidos dos programas implementados pelo governo federal, procurando dimensionar suas ressonâncias nas atuais políticas educacionais.

Sob essas condições, de forma preliminar, vale destacar que "o poder público tem a obrigação de oferecer uma escola que comporte a dinâmica de aprendizagem da população que pretende atingir." (KRAWCZYK, 2011 , p. 757). Nesse sentido, continua sendo um desafio a constituição de políticas públicas para a Educação do Campo, vinculadas a programas e estratégias que atendam às demandas contemporâneas. Isso porque se considera desejável que a Escola do Campo articule "os conhecimentos que os educandos têm o direito de acessar a partir do trabalho com a realidade, da religação entre educação com a cultura e com os conhecimentos científicos a serem apreendidos em cada ciclo da vida e de diferentes áreas do conhecimento." (MOLINA; FREITAS, 201 1, p. 27).

Em consonância com a proposta de Educação do Campo e seguindo as metas do Plano Nacional de Educação (2014-2024), o Governo Federal constituiu, em 2012, o Programa Nacional de Educação do Campo (Pronacampo). Visando favorecer o ensino nas escolas localizadas na área 
rural, o Programa buscou estratégias para assegurar a formação da Educação Básica e de Cursos Técnicos, a fim de melhorar a produtividade e garantir a distribuição de renda. Assim, o Pronacampo foi estruturado em cinco eixos, a saber: Gestão e Práticas Pedagógicas; Formação de Professores; Educação de Jovens e Adultos; Educação Profissional e Tecnológica; Infraestrutura Física e Tecnológica (MINISTÉRIO DA EDUCAÇÃO, 2012e). Com o intuito de reiterar o estudo em questão, observamos que cada um desses eixos estabelece ações/ programas que objetivam a efetivação das metas e, dentre eles, destacamos a seguir as quatro políticas de desenvolvimento que abrangem o Ensino Médio.

Primeiramente, sinalizamos o Programa Nacional do Livro Didático (PNLD) Campo, o qual tem por finalidade distribuir livros para os estudantes que frequentam o Ensino Fundamental e o Ensino Médio regular ou na modalidade de Educação de Jovens e Adultos. Nessa direção, o Programa intenta ofertar uma aprendizagem significativa, contextualizada e de acordo com as políticas de desenvolvimento da Educação do Campo. Por isso, a Resolução CD/FNDE n. 40, de 26 de julho de 201 l, prevê, no art. $2^{\circ}$, que, "para participar do PNLD Campo, as escolas beneficiárias deverão estar vinculadas às redes de ensino estaduais, municipais e do Distrito Federal que tenham firmado termo de adesão ao PNLD e também estar situadas ou manter turmas anexas em áreas rurais." (MINISTÉRIO DA EDUCAÇÃO, 2011). Portanto, o Programa PNLD Campo pretende melhorar a qualidade educacional das escolas localizadas nas áreas rurais disponibilizando coleções de livros didáticos, conforme a realidade dos jovens, e favorecendo o entrelaçamento entre conhecimento científico e saberes populares.

O Programa Nacional Biblioteca da Escola (PNBE) Temático, em uma direção próxima, propõe melhorias para as bibliotecas das escolas públicas que possuem cadastro no censo escolar, este desenvolvido pelo Instituto Nacional de Estudos e Pesquisas Educacionais Anísio Teixeira (Inep). ○ Programa objetiva disponibilizar materiais de aporte à prática pedagógica e acervo de obras literárias compostas por temáticas diversificadas, a fim de propiciar uma formação que valorize a cultura, buscando valores que contribuam para romper com exclusões presentes na sociedade brasileira, além de preconceitos e qualquer tipo de discriminação (MINISTÉRIO DA EDUCAÇÃO, 2009a). 
Assim, a Resolução n. 7, instituída em 20 de março de 2009, estabelece que o programa financiado pelo Fundo Nacional de Desenvolvimento da Educação (FNDE) tem como público-alvo os alunos e docentes da Educação Infantil, do Ensino Fundamental, do Ensino Médio e da modalidade Educação de Jovens e Adultos (EJA).

\section{O Programa Licenciatura em Educação do Campo (Procampo)} viabiliza a oferta de formação inicial aos docentes que atuam no Ensino Fundamental (anos finais) e no Ensino Médio nas Escolas do Campo, propiciando acesso aos cursos de Licenciatura nas Universidades Federais e em Institutos Federais de Educação, Ciência e Tecnologia. Considerando questões de temporalidade e territorialidade, o Programa prevê estrutura curricular em regime de alternância, com um período destinado para o desenvolvimento de atividade na escola e outro na comunidade. A formação Procampo tem como princípio a valorização da realidade da comunidade que vive nas áreas rurais; assim, o Programa, constituído com o envolvimento social, disponibiliza a Educação Básica nas Escolas do Campo (MINISTÉRIO DA EDUCAÇÃO, 2012c).

Dentre as políticas públicas de desenvolvimento voltadas para o Ensino Médio destinadas à Educação do Campo, encontramos também o Programa Integrado de Juventude (Projovem), instituído pelo Governo Federal. O Programa, implementado em 2005, conhecido como Saberes da Terra, foi estruturado após dois anos de sua consolidação como uma das modalidades que fazem parte do Projovem, a saber: adolescente, urbano, campo e trabalhador. $\bigcirc$ Programa propõe-se a oportunizar aos jovens a escolarização do Ensino Fundamental, quando não o frequentaram ou concluíram seus estudos no tempo adequado, por meio da Educação de Jovens e Adultos (EJA) e da qualificação profissional (MINISTÉRIO DA EDUCAÇÃO, 2012d).

No que se refere ao Projovem Campo - Saberes da Terra, destacamos que tem duração de dois anos e é ofertado em sistema de alternância. Cada estado fica responsável pelo seu formato, organizando-o de acordo com as características e especificidades dos trabalhos desenvolvidos em cada região. Desse modo, as atividades agregam um tempo na escola e outro na comunidade, objetivando a qualificação social e profissional, integrando os saberes do campo. Segundo o Programa, as propostas curriculares têm como 
base norteadora a Agricultura Familiar e a Sustentabilidade (MINISTÉRIO DA EDUCAÇÃO, 2009b). O Projovem Campo - Saberes da Terra pode ser também encontrado pela nomenclatura Programa EJA - Saberes da Terra.

Ao examinar esse conjunto de programas e políticas de desenvolvimento no contexto brasileiro, observamos que, dos investimentos e reformas desenvolvidos, poucos enfatizam o Ensino Médio do Campo. Partindo desse pressuposto, a seguir intencionamos apresentar problematizações acerca das questões curriculares, sinalizando os direcionamentos propostos nos documentos elaborados pelo Ministério da Educação e que orientam - Ensino Médio do Campo. É sabido que essa modalidade da Educação Básica ainda não apresenta os resultados almejados e, por isso, necessitase de investimentos para que realmente ocorram mudanças e melhorias em seu regime de implementação. Assim, consideramos, neste estudo, que a escolarização, como uma tarefa pública, não se restringe apenas ao âmbito profissional, mas envolve uma ampla gama de investimentos organizacionais, estruturais, financeiros e de novas propostas. Por isso, faz-se indispensável elaborar estratégias que proporcionem um ensino de qualidade aos jovens que cursam o Ensino Médio nas escolas do campo.

\section{TENDÊNCIAS E PERSPECTIUAS DO ENSINO MÉDIO DO CAMPO: UMA ANÁLISE DOS DOCUMENTOS CURRICULARES}

Buscando aprofundar a presente investigação, direcionamos nosso olhar para os estudos curriculares, com o objetivo de compreender as "políticas de constituição do conhecimento escolar." (SILVA, 2014). Reconhecendo que as propostas curriculares são derivadas de processos de seleção cultural, os estudos críticos contemporâneos reconhecem que os currículos e as práticas pedagógicas se apresentam "então articulados aos dispositivos políticos de atuação do Estado Moderno ao mesmo tempo em que interagem com as condições sociais e econômicas de seu momento histórico." (SILVA; PEREIRA, 2013, p. 886). As transformações sociais, em suas variadas nuances, 
desencadearam ações que foram decisivas para o sistema educacional, permitindo-nos compreender que o currículo "é produto das tensões, conflitos e concessões culturais, políticas e econômicas que organizam e desorganizam um povo." (APPLE, 2011, p. 71).

Por esses motivos, buscamos produzir um campo de problematização, por meio da leitura de diferentes autores, acerca dos aspectos que permeiam os estudos de currículo na contemporaneidade, interligando-os às questões atinentes ao Ensino Médio do Campo. Seguimos reforçando nossos argumentos, compreendendo que o sentido de currículo é produzido nos mais variados campos de atividades sociais, na medida em que se configura como um "projeto seletivo de cultura, cultural, social, política e administrativamente condicionado" (SACRISTÁN, 1998, p. 34, grifo do autor). Prosseguindo em direção próxima, porém em perspectivas teóricas diferentes, Young (2014, p. 201 ) nos ajuda a compreender que a responsabilidade escolar está atrelada ao modelo de educação que se intenta ofertar aos estudantes, ou seja, "é através desses processos em diferentes campos que os currículos reproduzem - ou não - as oportunidades sociais."

O currículo pautado em conteúdos que fazem parte da realidade dos jovens que estudam no campo, atrelado a outros saberes globais, pode ser uma possibilidade pertinente para melhorar a qualidade do ensino brasileiro. Nessa direção, faz-se indispensável proporcionar a expansão do desenvolvimento intelectual dos estudantes, elaborando estratégias de ensino que propiciem ao sujeito conhecer outras possibilidades, diferentes do seu contexto (YOUNG, 201 1). Iniciando nossas considerações sobre o tema em questão, entendemos serem pertinentes os esclarecimentos da Resolução CNE/CEB n. 2, de 28 de abril de 2008, no que se refere à Educação do Campo e suas populações. $\bigcirc$ art. $1^{\circ}$ prevê:

Art. $1^{\circ}$ A Educação do Campo compreende a Educação Básica em suas etapas de Educação Infantil, Ensino Fundamental, Ensino Médio e Educação Profissional Técnica de nível médio integrada com o Ensino Médio e destina-se ao atendimento às populações rurais em suas mais variadas formas de produção da vida - agricultores familiares, extrativistas, pescadores artesanais, ribeirinhos, assentados 
e acampados da Reforma Agrária, quilombolas, caiçaras, indígenas e outros. (MINISTERIO DA EDUCAÇÃO, 2008).

Para fins de complementaridade, considera-se Escola do Campo "aquela situada em área rural, conforme definida pela Fundação Instituto Brasileiro de Geografia e Estatística (IBGE), ou aquela situada em área urbana, desde que atenda predominantemente a populações do campo." (art. $1^{\circ}, \S 1^{\circ}$, II) (BRASIL, 2010). Com base nesses princípios, direcionamos nossa análise especificamente para o Ensino Médio do Campo. Encontramos fragmentos nos Marcos Normativos (MINISTÉRIO DA EDUCAÇÃO, 2012f) que enfatizam a necessidade de superar "a visão assistencialista que acompanha essa modalidade de educação, desde suas origens." (MINISTÉRIO DA EDUCAÇÃO, 2012f, p. 21). Para tanto, o documento cita iniciativas de alguns estados brasileiros que visam promover a expansão de estabelecimentos oficiais que ofereçam o Ensino Médio e, assim, cursos gratuitos de ensino técnico-industrial, agrícola e comercial.

Já no âmbito da Resolução CNE/CEB n. 1, de 03 de abril de 2002, a qual institui diretrizes operacionais para a Educação Básica nas escolas do campo, foi possível identificar excertos que interligam a Escola do Campo a questões pertinentes à realidade e aos saberes próprios dos estudantes, além da "memória coletiva que sinaliza futuros, na rede de ciência e tecnologia disponível na sociedade e nos movimentos sociais em defesa de projetos que associem as soluções exigidas por essas questões à qualidade social da vida coletiva no país." (art. $2^{\circ}$, parágrafo único) (MINISTÉRIO DA EDUCAÇÃO, 2002). Considerando essa previsão, o art. $4^{\circ}$ estabelece que:

Art. $4^{\circ} \bigcirc$ projeto institucional das escolas do campo, expressão do trabalho compartilhado de todos os setores comprometidos com a universalização da educação escolar com qualidade social, constituir-se-á num espaço público de investigação e articulação de experiências e estudos direcionados para o mundo do trabalho, bem como para o desenvolvimento social, economicamente justo e ecologicamente sustentável. (MINISTÉRIO DA EDUCAÇÃ O, 2002). 
E, ainda, em seu art. $7^{\circ}, \S 1^{\circ}$, ressalta que "o ano letivo, observado o disposto nos artigos 23, 24 e 28 da LDB, poderá ser estruturado independente do ano civil", no intuito de que sejam regulamentadas as estratégias, os espaços pedagógicos e os tempos de aprendizagem específicos de atendimento escolar do campo (MINISTÉRIO DA EDUCAÇÃO, 2002).

Dentre muitos desafios e propostas para o Ensino Médio do Campo previstos nos documentos, o Parecer CNE/CEB n. 1, de 01 de fevereiro de 2006, traz apontamentos sobre os dias letivos para a aplicação da Pedagogia de Alternância nos Centros Familiares de Formação por Alternância (CEFFA), considerando esta ser a melhor alternativa para a Educação Básica, "neste contexto, para os anos finais do Ensino Fundamental, o Ensino Médio e a Educação Profissional Técnica de nível médio, estabelecendo relação expressiva entre as três agências educativas - família, comunidade e escola." (MINISTÉRIO DA EDUCAÇÃO, 2006, p. 39). Isso porque, segundo o documento citado, os objetivos da Pedagogia da Alternância objetivam formar integralmente os jovens do meio rural, adequando os conteúdos a sua realidade e colaborando para a melhoria de vida na família e na comunidade (por meio da aplicação de conhecimentos técnico-científicos). Nesse sentido, os alunos passam um período na família/comunidade (duas semanas), alternado por outro período (uma ou duas semanas, em regime de internato ou semi-internato) no Centro de Formação, e, "após a conclusão do curso, o aluno recebe o histórico escolar (Ensino Supletivo ou Fundamental, Médio ou Profissional de nível técnico) e o diploma de formação profissional (Ensino Médio) ou de qualificação como profissional da agricultura (Ensino Fundamental)." (MINISTÉRIO DA EDUCAÇÃO, 2006, p. 41). Dessa forma:

Ocorre a inserção no próprio meio de origem com a geração de emprego, de renda e de riquezas. A relação entre teoria e prática desenvolve as pessoas e estas, por sua vez, desenvolvem seu meio. É o aprender a aprender! É a Educação do Campo em seu conceito mais atual e consentâneo com a realidade. (MINISTÉRIO DA EDUCAÇÃO, 2006, p. 43). 
As Diretrizes Curriculares Nacionais para o Ensino Médio (Resolução CNE/CEB n. 2/2012), de acordo com o disposto nas Diretrizes e Normas Nacionais respectivas do Campo (Resolução CNE/CEB n. 1/2002), ainda, estabelecem a exigência de reorganizar os tempos e espaços educativos a fim de concretizar uma organização curricular integradora. Nessa perspectiva, "a alternância pode potencializar esse processo formativo, trazendo as questões da vida para que as pessoas entendam sobre o que são, o que pensam e como agem" (MINISTÉRIO DA EDUCAÇÃO, 2012f, p. 226), uma vez que o projeto educativo pautado nesse modelo contribui para a construção de um novo tecido social e econômico para o desenvolvimento local (MINISTÉRIO DA EDUCAÇÃO, 2006). Por esse viés, pontuamos a necessidade de se refletir sobre as propostas curriculares que permeiam as práticas pedagógicas do Ensino Médio no Campo, visto que as políticas educacionais que enfatizam questões como assistencialismo, eficiência, bem como desenvolvimento de habilidades e competências para preparar os jovens para o trabalho do campo, reduzindo os conteúdos, são aspectos a serem repensados.

Com o intento de respeitar os objetivos da Educação do Campo no que se refere à oferta do Ensino Médio, a Resolução CNE/CEB n. 2/2008, em seu art. $5^{\circ}$, trata sobre a nucleação rural, a qual "poderá constituir-se em melhor solução, mas deverá considerar o processo de diálogo com as comunidades atendidas, respeitados seus valores e sua cultura." (MINISTÉRIO DA EDUCAÇÃ 0 , 2008). Porém, o $\S 1^{\circ}$ reitera a importância de, sempre que possível, garantir o deslocamento dos alunos do campo para o campo, evitandose o deslocamento para a cidade. Sempre que a nucleação rural for necessária, serão consideradas "as distâncias de deslocamento, as condições de estradas e vias, o estado de conservação dos veículos utilizados e sua idade de uso, a melhor localização e as melhores possibilidades de trabalho pedagógico com padrão de qualidade." (art. 10) (MINISTÉRIO DA EDUCAÇÃO, 2008).

Ao examinarmos as Diretrizes Curriculares Nacionais para o Ensino Médio apresentadas no Parecer CNE/CEB n. 5, de 04 de maio de 2011 , observamos um delineamento fundamental para as políticas curriculares no que se refere ao Ensino Médio do Campo: 
Esta modalidade da Educação Básica e, portanto, do Ensino Médio, está prevista no art. 28 da LDB, definindo, para atendimento da população do campo, adaptações necessárias às peculiaridades da vida rural e de cada região, com orientações referentes a conteúdos curriculares e metodologias apropriadas às reais necessidades e interesses dos estudantes da zona rural; organização escolar própria, incluindo adequação do calendário escolar às fases do ciclo agrícola e às condições climáticas; e adequação à natureza do trabalho na zona rural. As propostas pedagógicas das escolas do campo com oferta de Ensino Médio devem, portanto, ter flexibilidade para contemplar a diversidade do meio, em seus múltiplos aspectos, observados os princípios constitucionais, a base nacional comum e os princípios que orientam a Educação Básica brasileira. (MINISTÉRIO DA EDUCAÇÃO, 2012a, p. 160).

Encontramos, ainda, nas Diretrizes Nacionais para o Ensino Médio, definidas pela Resolução CNE/CEB n. 2/2012, importantes aspectos no que diz respeito às propostas curriculares destinadas para essa etapa. $\bigcirc$ documento evidencia, no art. $7^{\circ}$, o entrelaçamento entre a base nacional comum e outra parte diversificada, na qual seja "todo integrado, de modo a garantir tanto conhecimentos e saberes comuns necessários a todos os estudantes, quanto uma formação que considere a diversidade e as características locais e especificidades regionais." (MINISTÉRIO DA EDUCAÇÃO, 2012b). Essas indicações seguem as prescrições da Resolução CNE/CEB n. 2, de 28 de abril de 2008, no que se refere à oferta de apoio pedagógico aos alunos, o qual inclui "condições infra-estruturais adequadas, bem como materiais e livros didáticos, equipamentos, laboratórios, biblioteca e áreas de lazer e desporto." (art. 6º (MINISTÉRIO DA EDUCAÇÃO, 2008).

Quando consideramos os fragmentos e as análises expostas, compreendemos que os documentos selecionados para este estudo buscam atender aos princípios da Educação do Campo reiterados no Decreto n. 7.352, art. $2^{\circ}$, II, de 04 de novembro de 2010 (BRASIL, 2010), os quais envolvem o "respeito à diversidade do campo em seus aspectos sociais, culturais, ambientais, políticos, econômicos, de gênero, geracional e de raça e etnia", a fim de valorizar a identidade da Escola do Campo por meio de projetos político-pedagógicos, conteúdos e metodologias adequados às necessidades locais. Os documentos analisados no presente estudo indicam a preocupação 
com o desenvolvimento do contexto local e atividades que sigam os princípios pedagógicos delineadores do Ensino Médio e da Educação do Campo, de forma articulada. Além dessa consideração analítica, nossos argumentos reiteram a importância da escola como lugar privilegiado para a aquisição do conhecimento, interligando os contextos específicos e gerais que caracterizam a atualidade.

\section{CONCLUSÃO}

$\bigcirc$ artigo teve como propósito elucidar a trajetória da escolarização no campo, problematizando questões referentes à oferta para os jovens que cursam a última etapa da educação básica, atribuindo centralidade analítica para as questões do conhecimento escolar. Nessa direção, propôs-se elencar os fatores que influenciaram a constituição do Ensino Médio do Campo até a contemporaneidade. Não nos faltam indicativos para concordarmos com o previsto nos Marcos Normativos de que a superação da visão assistencialista para o contexto estudado se torna fundamental. A conjuntura educacional brasileira, sinalizada por Libâneo (2012, p. 16), apresenta características de um ensino dualista, no qual temos, por um lado, "a escola assentada no conhecimento, na aprendizagem e nas tecnologias, voltada aos filhos dos ricos, e, em outro, a escola do acolhimento social, da integração social, voltada aos pobres e dedicada, primordialmente, a missões sociais de assistência e apoio às crianças." Pensando no Ensino Médio do Campo, faz-se indispensável propiciar um ensino de qualidade que atenda às necessidades ligadas ao conhecimento escolar e que esses sujeitos tenham acesso a uma aprendizagem significativa. Em outras palavras, salientamos que, indiferentemente do contexto em que estejam inseridos, consideramos importante que todos tenham a possibilidade de aprender de forma justa e democrática, com acesso aos artefatos culturais e tecnológicos contemporâneos.

A contemporaneidade vem exigindo critérios pedagógicos mais desafiadores, e, por isso, concordamos com os apontamentos de Young (2014, p. 
198) de que "precisamos entender os currículos como formas de conhecimento especializado para podermos desenvolver currículos melhores e ampliar as oportunidades de aprendizado." Esse argumento se reafirma nas concepções do autor, pois a serventia da escola estaria em capacitar ou poder capacitar "os jovens a adquirir o conhecimento que, para a maioria deles, não pode ser adquirido em casa ou em sua comunidade, e para adultos, no seu local de trabalho." (YOUNG, 2007, p. 1294). Derivando pontuações do pensamento de Young, a educação poderia ser um meio para que os estudantes adquirissem conhecimento e transcendessem a experiência pessoal diária.

Direcionando nossos apontamentos para o Ensino Médio do Campo, essas reflexões tornam-se imprescindíveis na medida em que as concepções de currículo, educação e sociedade presentes no cotidiano escolar apresentam implicações na ordenação do sistema educativo e influenciam a possibilidade de os jovens vivenciarem diversas experiências. Por esses motivos, em nossa leitura, justificam-se os argumentos de Dussel (2009, p. 359), assegurando que "a escola hoje, mais do que nunca, deve ser o lugar capaz de nos pôr em contato com um mundo-outro [...] que nos confronta com o desconhecido, o que nos permite entender e desafiar nossos limites e nos faz mais abertos aos outros e a nós mesmos."

Ao examinarmos as políticas direcionadas para o Ensino Médio do Campo, concluímos que seus sentidos democráticos ainda são insuficientes como estratégia para o êxito dessa etapa da Educação Básica no campo, uma vez que assumem como ênfase a constituição de uma identidade para o indivíduo residente nesse contexto e tentam assegurar sua permanência. Ressaltamos, obviamente, a importância e a pertinência de tais considerações; entretanto, da mesma maneira com a qual exploramos desde a epígrafe deste artigo, reconhecemos a educação como a garantia de tempo livre àqueles grupos que historicamente seriam destinados ao mundo do trabalho.

Garantir tempo livre aos jovens pode ser uma possibilidade relevante para os debates acerca das dimensões públicas de escolarização, buscando equidade de oportunidade a fim de construirmos um mundo em comum. As políticas curriculares para o Ensino Médio, em aproximação à Educação do Campo, poderiam, de forma crítica e democrática, encarar a escola como 
"um espaço no qual somos expostos a coisas, e sermos expostos poderia ser considerado como sermos levados para fora." (MASSCHELEIN; SIMONS, 2014, p. 196). Em estudos posteriores, avançaremos nossa investigação em relação às políticas de constituição do conhecimento escolar para o Ensino Médio, cotejando as necessidades hodiernas advindas da Educação do Campo.

\section{REFERÊNCIAS}

ALMEIDA, D. B. A educação rural como processo civilizador. In: STEPHANOU, M.; BASTOS, M. H. C. (Org.). História e memórias da educação no Brasil Vol. III - Século XX. 4. ed. Petrópolis: Vozes, 201 l. p. 278-295.

APPLE, M. W. Repensando ideologia e currículo. In: MOREIRA, A. F. B.; SILVA, T. T. da (Org.). Currículo, sociedade e cultura. 12. ed. São Paulo: Cortez, 201 l. p. 49-69.

BRASIL. Decreto n. 7.352, de 04 de novembro de 2010. Dispõe sobre a política de educação do campo e o Programa Nacional de Educação na Reforma Agrária - PRONERA. Diário Oficial da União, Brasília, DF, 05 nov. 2010.

BRASIL. Emenda Constitucional n. 59, de 11 de novembro de 2009. Acrescenta $\S 3^{\circ}$ ao art. 76 do Ato das Disposições Constitucionais Transitórias para reduzir, anualmente, a partir do exercício de 2009, o percentual da Desvinculação das Receitas da União incidente sobre os recursos destinados à manutenção e desenvolvimento do ensino de que trata o art. 212 da Constituição Federal [...] com a inserção neste dispositivo de inciso VI. Diário Oficial da União, Brasília, DF, 12 nov. 2009.

BRASIL. Lei n. 4.024, de 20 de dezembro de 1961. Fixa as Diretrizes e Bases da Educação Nacional. Diário Oficial da União, Brasília, DF, 28 dez. 1961.

BRASIL. Lei n. 5.692, de 11 de agosto de 1971. Fixa Diretrizes e Bases para o ensino de $1^{\circ}$ e $2^{\circ}$ graus, e dá outras providências. Diário Oficial da União, Brasília, DF, 12 ago. 1971.

BRASIL. Lei n. 9.394, de 20 de dezembro de 1996. Estabelece as diretrizes e bases da educação nacional. Diário Oficial da União, Brasília, DF, 23 dez. 1996.

CALAZANS, M. J. C. Para compreender a educação do estado no meio rural: traços de uma trajetória. In: THERRIEN, J.; DAMASCENO, M. N. (Coord.). Educação e escola no campo. Campinas: Papirus, 1993. 
DUSSEL, I. A transmissão cultural assediada: metamorfoses da cultura comum na escola. Cadernos de Pesquisa, v. 39, n. 137, p. 351-365, 2009.

KOLLING, E. J.; NÉRY, I.; MOLINA, M. C. Por uma educação básica do campo. Brasília, DF: Fundação Universidade de Brasília, 1999.

KRAWCZYK, N. Ensino médio: empresários dão as cartas na escola pública. Educação \& Sociedade, Campinas, v. 35, n. 162, p. 1-12, jan./mar. 2014.

KRAWCZYK, N. Reflexão sobre alguns desafios do ensino médio no Brasil hoje. Cadernos de Pesquisa, v. 41, n. 144, p. 752-769, set./dez. 2011.

LIBÂNEO, J. C. O dualismo perverso da escola pública brasileira: escola do conhecimento para os ricos, escola do acolhimento social para os pobres.

Educação e Pesquisa, São Paulo, v. 38, n. 1, p. 13-28, 2012.

MASSCHELEIN, J.; SIMONS, M. A pedagogia, a democracia, a escola. Belo Horizonte: Autêntica, 2014.

MINISTÉRIO DA EDUCAÇÃO. Conselho Nacional de Educação. Câmara de Educação Básica. Parecer CNE/CEB n. 1, de 01 de fevereiro de 2006. Diário Oficial da União, Brasília, DF, 15 mar. 2006.

MINISTÉRIO DA EDUCAÇÃO. Conselho Nacional de Educação. Câmara de Educação Básica. Parecer CNE/CEB n. 5, de 04 de maio de 2011 . Diretrizes Curriculares Nacionais para o Ensino Médio. Diário Oficial da União, Brasília, DF, 24 jan. 2012a.

MINISTÉRIO DA EDUCAÇÃO. Conselho Nacional de Educação. Câmara de Educação Básica. Resolução CNE/CEB n. 1, de 03 de abril de 2002. Diário Oficial da União, Brasília, DF, 9 abr. 2002.

MINISTÉRIO DA EDUCAÇÃO. Conselho Nacional de Educação. Câmara de Educação Básica. Resolução CNE/CEB n. 2, de 28 de abril de 2008. Diário Oficial da União, Brasília, DF, 29 abr. 2008.

MINISTÉRIO DA EDUCAÇÃO. Conselho Nacional de Educação. Câmara de Educação Básica. Resolução CNE/CEB n. 2, de 30 de janeiro de 2012. Define Diretrizes Curriculares Nacionais para o Ensino Médio. Diário Oficial da União, Brasília, DF, 31 jan. 2012b. 
MINISTÉRIO DA EDUCAÇÃO. Fundo Nacional de Desenvolvimento da Educação. Conselho Deliberativo. Resolução CD/FNDE n. 40, de 26 de julho de 201 1. Dispõe sobre o Programa Nacional do Livro Didático do Campo (PNLD Campo) para as escolas do campo. Diário Oficial da União, Brasília, DF, 27 jul. 2011.

MINISTÉRIO DA EDUCAÇÃO. Fundo Nacional de Desenvolvimento da Educação. Conselho Deliberativo. Resolução CD/FNDE n. 7, de 20 de março de 2009. Dispõe sobre o Programa Nacional Biblioteca da Escola (PNBE). Diário Oficial da União, Brasília, DF, 23 mar. 2009a.

MINISTÉRIO DA EDUCAÇÃO. Programa de Apoio à Formação Superior em Licenciatura em Educação do Campo - Procampo. 2012c. Disponível em: <http://portal.mec.gov.br/par/194-secretarias-1 12877938/secad-educacao-continuada-223369541/17439-programa-de-apoio-a-formacao-superior-em-licenciatura-em-educacao-do-campo-procampo-novo>. Acesso em: 28 mar. 2016.

MINISTÉRIO DA EDUCAÇÃO. Programa Integrado de Juventude - Projovem. 2012d. Disponível em: <http://www.brasil.gov.br/educacao/2012/04/ programa-capacita-jovens-para-o-mercado-de-trabalho>. Acesso em: 10 mar. 2016.

MINISTÉRIO DA EDUCAÇÃO. Pronacampo. 2012e. Disponível em: <http:// portal.mec.gov.br/index.php?option $=$ com_content\&view $=$ article\&id $=18720$ :pronacampo\&catid= 194:secad-educacao-continuada >. Acesso em: 24 jun. 2016.

MINISTÉRIO DA EDUCAÇÃO. Secretaria de Educação Continuada, Alfabetização, Diversidade e Inclusão. Educação do Campo: marcos normativos. Brasília, DF: SECADI, $2012 f$.

MINISTÉRIO DA EDUCAÇÃO. Secretaria de Educação Continuada, Alfabetização e Diversidade. Secretaria de Educação Profissional e Tecnológica. Projeto Base Projovem Campo - Saberes da Terra. Brasília, DF: MEC, 2009b.

MOEHLECKE, S. $\bigcirc$ ensino médio e as novas diretrizes curriculares nacionais: entre recorrências e novas inquietações. Revista Brasileira de Educação, Rio de Janeiro, v. 17, n. 49, p. 39-58, jan./abr. 2012.

MOLINA, M. C.; FREITAS, H. C. de A. Avanços e desafios na construção da Educação do Campo. Em Aberto, Brasília, DF, v. 24, n. 85, p. 17-31, abr. 201 l. Disponível em: <http://emaberto.inep.gov.br/index.php/emaberto/article/viewFile/2562/1751 >. Acesso em: 17 fev. 2015. 
NASCIMENTO, M. N. M. Ensino Médio no Brasil: determinações históricas.

Publicações UEPG Ciências Humanas, Ponta Grossa, v. 15, n. 1, p. 77- 87. 2007.

RAMOS, M. N. O ensino médio ao longo do século XX: um projeto inacabado. In: STEPHANOU, M.; BASTOS, M. H. C. (Org.). Histórias e memórias da educação no Brasil - vol. III - Século XX. 4. ed. Petrópolis: Vozes, 2011 . p. 229-242.

ROMANELLI, O. de O. História da Educação no Brasil. 37. ed. Petrópolis: Vozes, 2012.

SACRISTÁN, J. G.; GÓMEZ, A. I. P. O que são os conteúdos do ensino? In: SACRISTÁN, J. G.; GÓMEZ, A. I. P. (Org.). Compreender e transformar o ensino. 4. ed. Porto Alegre: Artmed, 1998. p. 149-195.

SACRISTÁN, J. G.; GÓMEZ, A. I. P. ○ que significa o currículo? In: SACRISTÁN, J. G. (Org.). Saberes e incertezas sobre o currículo. Porto Alegre: Penso, 2013. p. 16-37.

SILVA JÚNIOR, A. F. da; BORGES NETTO, M. Por uma educação do campo: percursos históricos e possibilidades. Entrelaçando - Revista Eletrônica de Culturas e Educação, n. 3, ano 2, p. 45-60, nov. 2011.

SILVA, R. Comunidades como espaço de intervenção pedagógica: um estudo da docência no ensino médio. Revista Brasileira de Educação, v. 19, n. 59, p. 945-966, 2014.

SILVA, R. Políticas de ampliação da jornada escolar para o Ensino Médio no Rio Grande do Sul: um estudo sobre o conhecimento escolar. Ensaio: avaliação e políticas públicas em educação, v. 23, n. 89, p. 869-900, 2015.

SILVA, R. R. D. da; PEREIRA, A. L. V. Políticas de Constituição do Conhecimento Escolar na Pesquisa Educacional Brasileira. Cadernos de Pesquisa, v. 43, n. 150, p. 884-905, set./dez. 2013.

SOUZA, R. F. de. História da organização do trabalho escolar e do currículo no século XX. São Paulo: Cortez, 2008.

YOUNG, M. ○ futuro da educação em uma sociedade do conhecimento: a defesa radical de um currículo disciplinar. Caderno de Educação, v. 38, p. 395-416, jan./abr. 2011.

YOUNG, M. Para que servem as escolas? Educação e Sociedade, Campinas, v. 28, n. 101, p. 1287-1302, set./dez. 2007. 
YOUNG, M. Teoria do currículo: o que é e por que é importante. Cadernos de Pesquisa, v. 44, n. 151, p. 190-202, 2014.

Recebido em:: 09 de agosto de 2017 Aceito em:: 03 de abril de 2018

Endereço para correspondência: Praça da Bandeira, 354, Centro, 99700-010, Erechim, Rio Grande do Sul, Brasil; paolinebresolin@hotmail.com 
